\title{
How Does Type of Orthography Affect Reading in Arabic and Hebrew as First and Second Languages?
}

\author{
Raphiq Ibrahim ${ }^{1,2^{*}}$, Asaid Khateb ${ }^{1,2}$, Haitham Taha ${ }^{1,2,3}$ \\ ${ }^{1}$ The Edmond J. Safra Brain Research Center for the Study of Learning Disabilities, Faculty of Education, \\ University of Haifa, Haifa, Israel \\ ${ }^{2}$ Department of Learning Disabilities, University of Haifa, Haifa, Israel \\ ${ }^{3}$ Sakhnin College for Teachers’ Education, Sakhnin, Israel \\ Email: *raphiq@psy.haifa.ac.il
}

Received December $18^{\text {th }}, 2012$; revised January $2^{\text {nd }}, 2013$; accepted January $10^{\text {th }}, 2013$

\begin{abstract}
This study aimed to examine the effects of visual characteristics of Arabic orthography on learning to read compared to Hebrew among Arabic and Hebrew bilinguals in an elementary bilingual education framework. Speed and accuracy measures were examined in reading words and non-words in Arabic and Hebrew as follows: Arabic words and non-words composed of connected and similar letters, words and non-words composed of connected and non-similar letters, and words and non-words composed of unconnected letters. In Hebrew, words and non-words composed of similar letters and non-similar letters. It was found that Arabic speakers showed an almost equal control in all reading tasks in both languages whereas, Hebrew speakers showed better performance in their mother tongue in all reading tasks. In Arabic, the best performance was in reading words and non-words that was unconnected. Based on these findings, it was concluded that Hebrew speakers did not succeed in transferring their good ability in reading their mother tongue to reading the second language, apparently due to the unique nature of the Arabic orthography. Our findings with regard to the cross-linguistic research literature as well as the specific features of Arabic language are discussed.
\end{abstract}

Keywords: Reading; Arabic; Hebrew; Orthography; Visual Complexity; Diglossia

\section{Introduction}

Research on bilingualism over the past three decades has focused on different issues including the effects of bilingualism on cognitive and linguistic development. The consensus on this issue today may be summarized thus: although bilinguals have a more complex and possibly multi-structured mental lexicon which is influenced by the idiosyncratic context in which the languages have been learned and by the structural relations between the languages (e.g., de Groot, 1992), this complexity need not result in differential cortical organization of linguistic abilities between bilinguals and monolinguals (Paradis, 2009). Bialystok (2001) claimed that exposure to more than one language at an early age results in heightened awareness of the arbitrary and phonological aspects of language. In a previous study, Arab children evince higher levels of phonological abilities than monolingual Hebrew speakers (Eviatar \& Ibrahim, 2000). Alphabetic orthography, like English and Hebrew, phonological awareness is a very good predictor of success in reading acquisition (Share, Jorm, Maclean, \& Matthhews, 1984). In turn to Arabic, the opposite finding has been reported in previous study that examined the relationship between phonological abilities and various reading measures in first grade in Arabic children learning to read Arabic and in Hebrew (monolinguals) and Russian (bilinguals) children learning to read Hebrew (Ibrahim, Eviatar, \& Aharon Peretz, 2007). The authors suggested that learning to read in Arabic is more challenging than in Hebrew. One possible answer to this is that this is an

"Corresponding author. effect of the diglossia. In previous study it has been shown that skilled adult readers of Arabic also read more slowly than skilled adult readers of other languages (Azzam, 1993). Therefore, diglossia cannot be the only reason for this pattern. In addition, we wondered, what could be blocking the facilitative effect of phonological awareness. In this study, this question will be examined directly among children learning to read Arabic and Hebrew and studying in similar conditions in a bilingual education framework.

\section{Arabic and Hebrew Orthographic Characteristics}

Arabic is a typical case of diglossia. According to Saieghhaddad (2005), modern standard Arabic (MSA) is the language used throughout the Arabic speaking world for writing and some other formal functions, such as speeches and religious sermons, while the spoken Arabic vernacular (SAV) is the language used for everyday conversation. The classical literary version is studied in school and is not acquired naturally without formal learning. Ibrahim (2009) reported that learning LA appears to be, in some respects, more like learning a second language than like learning the formal register of one's native language. As opposed to the Arabic, diglossia does not exist in Hebrew.

In addition to its diglossic nature, the orthography of Arabic plays essential roles in assessing reading and examining the predicative power of different processes.

The unique characteristics of Arabic (and to little extent in Hebrew) orthography are many and complex, so only some, those most pertinent to the present investigation will be 
reviewed briefly here. These are the positional variants of letters, the consonant diacritics, and letter ligature. Indeed, a number of letters (graphemes) share the same form (derived from Nabatean which had fewer consonants) and are distinguished only by the position and the number of consonant (dot) diacritics For example, the letters $/ ت /, / \mu$ and $/ ث /$ represent the consonants $/ \mathrm{t} / \mathrm{h} / \mathrm{b} / \mathrm{and} / \mathrm{th} /$ respectively. Some adaptations of the Arabic abjad (e.g., Sindhi in southern India), include up to 7 or even 8 diacritical variants of the identical letter-form. An additional unique feature of Arabic orthography is that the majority of letters vary in shape according to position in the word; wordinitial, medial or word-final position. It is worthy to emphasize that letter position also imply a change on the letter variant causing a little change $(/ / / b / b /)$ or a large change $(/ 0 / \alpha / \& / \Delta /)$ on the letter shape (for more examples see Appendix A). Six letters, however, have only two variant shapes which depend not only on the position in the word but also on the preceding letter $(/ \mathrm{J} / \mathrm{r} / ; / \mathrm{j} / \mathrm{z} / ; / \mathrm{s} / \mathrm{d} / ; / \mathrm{j} / \mathrm{th} / ; / \mathrm{g} / \mathrm{w} / ;$ and $/ / / \mathrm{a} /)$. This subset of letters may connect only from the right side $(/ 2 \mathrm{~g} / \mathrm{Lawh} /)$ but not from the left (ولد/Walad/). This sub-group of letters, therefore, may appear to the reader as more "distinct", because visually separated from adjacent letters. Unlike the Arabic orthography, in Hebrew the majority of letters don't vary in shape according to position in the word. Only five letters, נn, $\boldsymbol{\eta}, \mathrm{m}, \mathrm{g}$, $\mathrm{p}, \mathrm{y}, \mathrm{tz}, \mathrm{J}, \mathrm{h}$, have two forms depending on whether they appear in word-final or in other positions. Generally, the shallow version of the Hebrew orthography where every phoneme is represented by either consonant or diacritical mark is acquired relatively easily with typically developing first grade children reaching decoding accuracy by the end of the first grade (Shatil, Share, \& Levin, 1999). This is in contrast to the acquisition of basic reading skills in Arabic.

Besides, the written vowelization system is considered as one of the unique features of the written Arabic. Written Arabic and Hebrew words could be vowelized by diacritical marks added above and below the letters within the word. In the case of vowelized written words, the written patterns are considered as shallow orthography, while in the case of non-vowelized written words, the orthography is considered as a deep one. In this case, the phonology is not reflected throughout the orthographic pattern alone but other context cues are needed. Deep orthographic patterns usually appear in texts dedicated to adult readers (Abu-Rabia, 2000).

\section{Research on Orthography}

Within the orthographic patterns of the written words, some of the letters can be connected with former and subsequent letter, while other letter can be connected only with the former letters. As a result different types of written words can be produced: 1) fully connected; 2) partially connected; and 3) nonconnected words (i.e. words appearing with the basic forms of the letters). Recent findings showed that these differences of the internal connectivity of the written words in Arabic have an impact on the time course of early brain electric responses during the visual processing of letters (Ibrahim, Eviatar, \& Aharon-Peretz, 2002; Eviatar, Ibrahim, \& Ganayim, 2004) and written Arabic words (Taha, Ibrahim, \& Khateb, 2012). These results complement those reported by Rao, Vaid, Srinivasan and Chen (2011), where native Urdu readers read Urdu more slowly than Hindi. These authors suggested that this is due to two factors: orthographic depth, where the relations between graph- emes and phonemes are more regular in Hindi than in Urdu (which has a consonantal script, like Arabic); and the greater visual complexity of Urdu orthography than Hindi orthography.

A study by Taouk and Coltheart (2004), investigated learning to read in Arabic between children and adults. In one experiment they attempted to examine naming of real pronounceable "position-illegal" words; which are words written with a wrong letter variant according to its position. They found that children's word reading was significantly impaired when incorrect positional variants were substituted for the correct variants. This finding provides evidence that positional variants of letters affect word reading. A recent study by Abdelhadi, Ibrahim and Eviatar (2011) examined how orthographic complexity can affect vowel identification between $3^{\text {rd }}$ and $6^{\text {th }}$ grade. They used a vowel identification task with stimuli in Arabic and Hebrew at three levels of lexicality; real words, pseudo-words and nonletters. Each level included three categories; separated letters, ligatured or connected letters and connected letters with vowel diacritics. The participants were required to identify a specific vowel, fatHa or Patax. The highest performance was predicted for separated letters, followed by connected letters, while the poorest performance was expected on stimuli with connected letters with vowel diacritics. The results were not consistent with the hypothesis; unexpectedly, children from both grades responded faster to letter strings with connected letters (both words and pseudo-words). These results suggested that $3^{\text {rd }}$ and $6^{\text {th }}$ graders used a different perceptual strategy when the stimuli were more word-like (e.g., comprised of connected letters) than when they were less word-like (e.g., comprised of disconnected letters).

\section{The Linguistic Reality in Israel}

The education system in Israel maintains the existing detachment between Jews and Arabs: schools are nationallyseparated. Although Arabic is considered as a formal language in the country, Jewish students are less exposed to Arabic language in particular and to Arabic culture in general than Arab students who study extensively Hebrew language, literature and culture (Al-Hag, 2003; Amara \& Mar I, 2002).

In Israel, bilingual schools emphasize the symmetry between the two languages, Arabic and Hebrew, in every teaching measure. Therefore, reading constitutes a fundamental skill in the acquisition of every language. Reading contains the ability to connect reading symbols to meaningful word for the sake of text decoding. From theoretical view, accepted theory concerning the field of learning of second language and bilingualism ascribes academic success and the acquisition of second language in the level of the first language (Cummins, 1991, 2000). According to Cummins (2000), as much as the level of linguistic expertise in the first language increases (passes certain threshold) over certain level of skillfulness higher than in the second language (another higher threshold), appear the cognitive growth.

\section{The Current Study}

In this study we postulate that the level of performance in reading tasks (the speed and accuracy of reading) in Arabic and Hebrew language (correspondingly) may reflect the different nature of the transfer to second language. Native Hebrew speakers may find more difficulty in learning Arabic as a second 
language than do native Arabic speakers when learning Hebrew, this difference results from the complexity of the Arabic language. According to the above mentioned postulation, an academic success in learning second language is only dependent on skills acquired in first language, and therefore according to Cummins's interdependence hypothesis, we may expect that there are no differences between the two bilingual groups in all the other influencing conditions, i.e. age, the period of exposure to second language and learning environment. In addition, this study examines the unique characteristics of Arabic orthography on the speed and accuracy measures when reading words and non-words in Arabic and Hebrew as first and second language.

The hypotheses of the study:

1) As far as accuracy and speed are concerned, we predict the level of performance will be better in tests examining reading in first language than reading in the second language. According to Cummins interdependence hypothesis, academic success in learning second language is only dependent on skills acquired in the first language.

2) We predict the performance in reading tests in Hebrew will be at a similar level or even better than reading tests in Arabic beyond groups. In their study, (Ibrahim, Eviatar, \& Aharon-Peretz, 2002) explained that this mostly results from two reasons: first, the orthographical complexity of the Arabic language and second, the status of written Arabic (Literary) which is considered by some authors as a second language (Ibrahim \& Aharon-Peretz, 2005; Eviatar \& Ibrahim, 2001; AbuRabia, 2000; Saiegh-Haddad, 2003, 2004).

3) Among native Arabic speakers, reading words with disconnected letters in Arabic is better (in terms of accuracy and speed) than reading words with connected letters. According to Azzam (1993), the major problem is that children have to remember tree or four shapes for each letter according to the position in the word and the child's ability to distinguish between letters based on tiny differences of a single characteristic or the position of dots in letters.

\section{Method}

Participants: 49 participants ( 32 from $3^{\text {rd }}$ grade and 17 from $4^{\text {th }}$ grade) with an average age of 9.3 years participated in this study. They were recruited from two bilingual schools in the north and center of the country where the study was conducted. Participants from the two groups were matched with regard to age, general ability, and the level of reading (educators chose children with commanding performance in reading in the two languages Arabic and Hebrew and none of them was diagnosed with learning disabilities). In the bilingual educational schools participated, literacy in Hebrew and literacy in Arabic is acquired in parallel from first grade. Children receive equal amounts of instruction in each language daily by both Hebrew and Arabic L1 teachers. Therefore the teaching method planned to be similar in two languages.

Stimuli: Three types of lists of words in Arabic were constructed: words with connected and similar letters, words with connected and non-similar letters and words non-connected letters (see Table 1 for example). In Hebrew, two lists of words were constructed: words with similar letters and words with non-similar letters (see Table 2 for example). This difference is due to the fact that Hebrew letters do not connect with each other. For each word sub-list, a list of non-words was established. This allowed examining the process of pure encoding of reading in comparison with the process of structural reading of familiar words.

In all list, non similar (non-cognate) words from literary and non-literary Arabic (spoken) were chosen. This step was taken to avoid the possibility that similar shapes cause to bias scores.

Before, conducting the experiment, the frequency of words in stimulus list was assessed. For this purpose, the initial word list included 240 words in Arabic (divided into three sub-lists defined on the basis of their orthographic characteristics) and 160 words in Hebrew (divided into two groups based on their orthographical characteristics). The initial Arabic and Hebrew word lists established with the of language teachers from other schools in the neighboring area. The words of all lists were then introduced in a questionnaire of frequency which was filled by children. Here, they had decide how frequent was each word using a scale ranging between 1 (rare) and 5 (very frequent). Based on the results of this assessment, 24 words whose mean frequency ranged between $1.5-3.5$ points were finally retained for each sub-list. The rationale for using this middle frequency range was to neutralize as much as possible the factor of word frequency.

Table 1.

Experimental conditions in Arabic.

\begin{tabular}{|c|c|c|c|c|c|}
\hline \multicolumn{2}{|c|}{$\begin{array}{c}\text { Words which consist of letters that is } \\
\text { disconnected }\end{array}$} & \multicolumn{2}{|c|}{$\begin{array}{l}\text { Words which consist of dissimilar letters and } \\
\text { connected }\end{array}$} & \multicolumn{2}{|c|}{$\begin{array}{l}\text { Words which consist of similar letters and } \\
\text { connected }\end{array}$} \\
\hline non-word & word & non-word & word & non-word & word \\
\hline أَزْوان & أَوْزان & ذَيْعام & مَذْياع & بَتُنات & تَنْتَاب \\
\hline azwan & awzan & thaya'am & methyaa' & Batnat & tantab \\
\hline
\end{tabular}

Table 2.

Experimental conditions in Hebrew.

\begin{tabular}{|c|c|c|c|}
\hline \multicolumn{2}{|c|}{ Words which consist of dissimilar letters } & \multicolumn{2}{|c|}{ Words which consist of similar letters } \\
\hline A non-word & A word & A non-word & A word \\
\hline זָזהוּל & זדוֹוּב & דָחוּר & 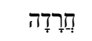 \\
\hline zahol & zahov & dahor & harad \\
\hline
\end{tabular}


It should be noted that the number of syllables and length of the words were controlled between Arabic and Hebrew. As for the non-words (which also were comparable to words in length and number of syllables), they were formed by changing one or two letters in the word or by substituting the position of some letters within each real word. All together, the study included six sub-lists in Arabic (of 24 items each) and four sub-lists in Hebrew (also of items).

Concerning the matter of examining the reliability of tasks, an examination of the measure reliability of different tasks was conducted based on Alfa Cronboch. (See Table 3).

From Table 3, it can be inferred that beyond the language groups, grades' reliability and speed of reading in different tasks ranged between .76 and .97 .

Procedure: The study took place inside the school in quiet room, individually for each participant. The meeting with each participant started with a short acquaintance aimed at creating a comfortable atmosphere while providing a brief explanation for the essence of the meeting in order to remove any concern, discomfort or hesitation. When the participant confirmed his readiness to start the tasks he/she was instructed to read ten sub-lists (hereafter tasks) in Arabic and Hebrew as fast and accurately as possible. The order of the presentation of the tasks was balanced across participants. Four short training lists were prepared so as familiarize the participants with the different tasks. Before starting each task, they were informed that their reading time of each tasks will be monitored using a stopwatch. In addition, a digital recorder registered their reading during the successive tasks for assessing off-line their reading accuracy.

\section{Results}

The analysis of the reading accuracy and speed in the native language showed that both reveal a good reading performance among the two groups of participants (native Arabic speakers and native Hebrew speakers) concerning speed and accuracy in the different task in their native language. Furthermore, very important results were found in relation to the difference status of Arabic language for native Arabic speakers and as a second language for native Hebrew speakers. This is in comparison to the status of Hebrew language for the two groups of speakers. Decisive effect of Arabic writing characteristics on the acquisition of this language was demonstrated by tyro readers. The average time of reading and percentages of accuracy in all reading tasks (reading separated words and reading text) in the two languages were the dependent variables.

The results of each hypothesis mentioned at the introduction are separately presented as the basic question which stands at the core examination is: is learning to read in Arabic language more difficult than Hebrew?

The average-time of reading and percentages of accuracy were analyzed as the native language (Arabic speakers and
Hebrew speakers), the language of the test (Arabic and Hebrew) and the type of the test (reading words and reading text) were served as independent variables. Regarding the issue of the two types of tasks (reading words and reading text) two analyses were conducted:

In the first analysis, the variable of the type of tests included three levels of different types of words (connected and similar, connected and dissimilar, and disconnected).

Examining differences in reading accuracy of native language on the basis of native language:

One-way analysis of variance of the grade in reading words in native language on the basis of native language was carried out and significant results were found $\mathrm{F}(1,47)=15.47, p<.001$, $\eta_{p}^{2}=.25$. Native Arabic speakers are more successful $(\mathrm{M}=$ 97.62, $\mathrm{SD}=1.78$ ), than their counterparts (native Hebrew speakers) $(\mathrm{M}=93.73, \mathrm{SD}=4.26)$.

Examining difference in the speed of reading words in native language on the basis of native language:

Here a one-way analysis of variance in the speed of reading words in mother language on the basis of native language was carried out and significant results were found $\mathrm{F}(1,47)=19.80, p$ $<.001, \eta_{p}^{2}=.30$. Hebrew speakers $(\mathrm{M}=34.40, \mathrm{SD}=10.68)$, are faster than their counterparts (Arabic speakers) $(\mathrm{M}=50.15$, $\mathrm{SD}=13.32$ ). It should be pointed out that compatibility in the number of syllables and the length of words in each task in the two languages (Arabic and Hebrew) was conducted.

Examining differences in the speed of reading Arabic words on the basis of native language and type of words:

Here are two-way analysis of variance in the speed of reading words in Arabic on the basis of native language and type of words was conducted with repeated measurements for type of words and significant differences were found $(\mathrm{F}(1,47)=55.35$, $\left.p<.001, \eta_{p}^{2}=.54\right)$. Arabic speakers $(\mathrm{M}=50.15, \mathrm{SD}=13.32)$ were faster than their counterparts (Hebrew speaker) $(\mathrm{M}=$ $128.57, \mathrm{SD}=53.80)$. In addition differences were also found on the basis of type of words $\mathrm{F}(5,235)=48.11, p<.001, \eta_{p}^{2}$ $=.51$. An interaction based on native language and type of words was found $\mathrm{F}(5,235)=20.26, p<.001, \eta_{p}^{2}=.30$. To examine the source of this interaction, researchers carried out a Post-Hoc test. It was found that regarding to test 5 (words with disconnected letters), Arabic speakers were faster than Hebrew speakers in comparison to other types of words. In addition, regarding test 6 (non-words with disconnected letters), Arabic speakers were faster in comparison to tests 2, 3 and 4. Furthermore, it was also found that Hebrew speakers were faster in reading words 4,5 and 6 , than words 1,2 and 3, and they were also slower in reading words from type 4 than words from types 5 and 6.

Examining differences of accuracy in reading words in Arabic language on the basis of native language and the type of word:

Table 3.

Accuracy and rates in reading Arabic and Hebrew words.

\begin{tabular}{|c|c|c|c|c|}
\hline Task & Mean & SD & $\alpha$ (Cronbach) & Total items \\
\hline Accuracy in reading Arabic words & 81.22 & 22.57 & .97 & 6 \\
\hline Reading rate of Arabic words & 83.76 & 53.32 & .96 & 6 \\
\hline Accuracy in reading Hebrew words & 95.73 & 4.29 & .76 & 4 \\
\hline Reading rate of Hebrew words & 46.62 & 20.23 & .95 & 4 \\
\hline
\end{tabular}


Two-way analysis of variance of grade in reading words in Arabic on the basis of native language and the type of word with repeated measurements for the type of word was conducted. Significant differences was found accordingly $\mathrm{F}(1,47)=$ 34.32, $p<.001, \eta_{p}^{2}=.42$. Arabic speakers $(\mathrm{M}=94.32, \mathrm{SD}=$ $3.90)$, were more successful than Hebrew speakers $(M=67.53$, $\mathrm{SD}=23.86)$. In addition differences in the type of words were found $\mathrm{F}(5,235)=30.54, p<.001, \eta_{p}^{2}=.39$. Here there is an interaction based on native language and the type of word $\mathrm{F}(5,235)=17.71, p<.001, \eta_{p}^{2}=.27$.

To examine the source of this interaction, a post-hoc test was carried out. It was found that Arabic speakers were more successful in words of the type 5 (words with disconnected letters) and they were also more successful in words of the type 6 (non-words with disconnected letters) in comparison to words of the type 2 (non-words with connected and similar letters.

Examining difference in the speed of reading words in Hebrew language based on native language and type of word:

Researchers conducted a two-way analysis of variance in the speed of reading words in Hebrew based on native language and type of words with repeated measurement for the type of word. Significant differences based on native language were found $\mathrm{F}(1,47)=18.24, p<.001, \eta_{p}^{2}=.28$. Hebrew speakers $(\mathrm{M}=34.93, \mathrm{SD}=10.68)$, were faster than Arabic speakers $(\mathrm{M}$ $=55.79, \mathrm{SD}=20.97)$. In addition, differences were found concerning the type of words $\mathrm{F}(3,141)=18.63, p<.001, \eta_{p}^{2}$ $=.28$. Therefore, there is an interaction on the basis of native language and the type of word $\mathrm{F}(3,141)=13.56, p<.001, \eta_{p}^{2}$ $=.22$. To examine the source of this interaction, a Post-Hoc test was carried out.

It was found that among Arabic speakers, no differences were found in the speed of reading based on type of word. It was also found that Hebrew speakers were faster in reading words with dissimilar letters than reading words with similar letters or non words. They were also faster in reading words with similar letters than reading non-words with similar and dissimilar letters.

Examining differences in accuracy in reading words in $\mathrm{He}$ brew based on native language and type of word:

Tow-way analysis of variance in the grade of reading words in Arabic based on native language and the type of word with repeated measurements for the type of word was conducted. Significant differences were found regarding native language $\mathrm{F}(1,47)=8.22, p<.01, \eta_{p}^{2}=.15$. Hebrew speakers, $(\mathrm{M}=$ 97.62, $\mathrm{SD}=1.78)$, were more successful than Arabic speakers $(\mathrm{M}=94.31, \mathrm{SD}=5.05)$, though no differences were found concerning the type of word $\mathrm{F}(3,141)=.74, p>.05, \eta_{p}^{2}=.02$. Thus, there was no interaction on the basis of native language and type of word $\mathrm{F}(3,141)=.43, p>.05, \eta_{p}^{2}=.02$.

Examining differences in the speed of reading words based on native language and the language of test:

Tow-way analysis of variance of the speed of reading words based on native language and the language of test with repeated measurement for the language of test was conducted. Significant differences were found regarding native language $\mathrm{F}(1,47)$ $=18.59, p<.001, \eta_{p}^{2}=.28$. Arabic speakers $(\mathrm{M}=52.97$, $\mathrm{SD}=16.57)$, were faster than Hebrew speakers $(\mathrm{M}=81.48$, SD $=29.37)$, and here significant differences were found regarding the language of test $\mathrm{F}(1,47)=80.43, p<.001, \eta_{p}^{2}=.63$. Among all participants, it was found that they were faster in reading in Hebrew $\mathrm{M}=45.09, \mathrm{SD}=20.23$ than Arabic $(\mathrm{M}=$ $89.36, \mathrm{SD}=53.32$ ), and this is beyond the native language
$\mathrm{F}(1,47)=102.22, p<.001, \eta_{p}^{2}=.69$. Finally, an interaction was found based on native language and the language of test $\mathrm{F}(1,47)=102.22, p<.001, \eta_{p}^{2}=.69$. A post-hoc examination suggests that for native Arabic participants, no differences were found between reading words in Arabic $(\mathrm{M}=50.15, \mathrm{SD}=$ 13.32), and reading words in Hebrew $(\mathrm{M}=55.78, \mathrm{SD}=20.97)$. On the other hand, for native Hebrew participants, the speed of reading words in Arabic $(\mathrm{M}=128.57, \mathrm{SD}=53.80)$, is longer than the speed of reading words in Hebrew $(\mathrm{M}=34.39, \mathrm{SD}=$ 10.68). It was also found that native Arabic readers' speed of reading Arabic is faster than native Hebrew readers. Conversely, native Hebrew readers' speed of reading Hebrew is faster than the speed of native Arabic.

Examining differences in accuracy of reading words based on native language and the language of test:

This research reveals another important finding that is consistent with a line of earlier studies which suggested that the status of literary Arabic is equal to the second language for native Arabic readers. According to this finding, native Arabic rehears' performances in Arabic reading tasks were not different from their performances in Hebrew reading tasks (Actual second language). On contrary, native Hebrew readers' performance in reading Hebrew tasks was significantly better.

Here, researchers conducted a tow-way analysis of variance for grade in reading words based on native language and the language of test with repeated measurement, and significant differences related to native language were found $\mathrm{F}(1,47)=$ 23.14, $p<.001, \eta_{p}^{2}=.33$. It was also found that native Arabic speakers were more successful $(\mathrm{M}=94.31, \mathrm{SD}=3.94)$, than their Hebrew counterparts $(\mathrm{M}=82.57, \mathrm{SD}=12.13)$. Therefore, differences related to the language of test were also found $\mathrm{F}(1,47)=43.77, p<.001, \eta_{p}^{2}=.48$ accordingly there is an interaction based on native language and the language of test $\mathrm{F}(1,47)=43.84, p<.001, \eta_{p}^{2}=.48$. Graph 5 shows the received interaction (See Figure 1).

According to a Post-Hoc examination, for native Arabic participants, no differences were found in accuracy of reading words in Arabic $(\mathrm{M}=94.32, \mathrm{SD}=3.90)$ and reading words in Hebrew $(\mathrm{M}=94.31, \mathrm{SD}=5.05)$. On the contrary, for native Hebrew participants, the level of accuracy in reading words in Hebrew $(\mathrm{M}=97.62, \mathrm{SD}=1.78)$, was higher than reading words in Arabic $(\mathrm{M}=67.53, \mathrm{SD}=23.86)$. In addition, concerning reading Arabic words, native Arabic readers were better than

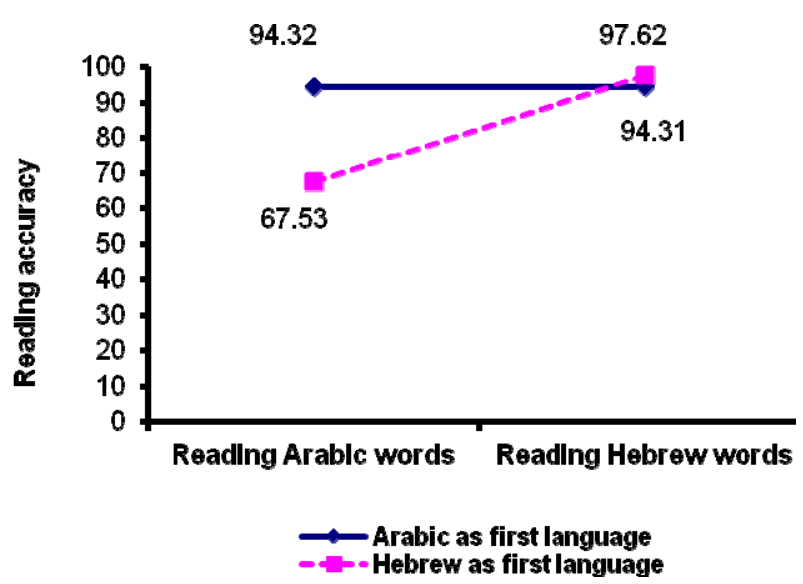

Figure 1.

Interaction of reading words accuracy by the subject native language. 
native Hebrew readers. Yet, concerning reading words in Hebrew, no differences were found between the two groups.

\section{Discussion}

The analysis of the study's results is conducted on the basis of Cummins's (1979-1981) interdependence hypothesis. According to this hypothesis a good linguistic ability in the first language predicts similar ability in the second language. Consequently, native Hebrew and Arabic speakers would have been expected to read in second language at a similar level (of speed and accuracy) to their native languages. Yet it was found that native Arabic speakers read significantly better in Hebrew than native Hebrew speakers read in Hebrew. These findings emphasize that learning to read in Arabic language more challenging and than reading in Hebrew even though Arabic and Hebrew have a similar nominal basis.

In the course of the current study, tasks the level of performance was compared with reading separated words and nonwords in Arabic and Hebrew, when the unique characteristics of Arabic orthography were greatly considered from a formative point of view. In this regard, the purpose was to clarify emperically whether Arabic language is more difficult in processing than Hebrew. As it has been planned, the two populations whose mother languages are different are simultaneously and at the same extent exposed to reading and writing in the second language in the same educational frame; two bilingual schools in Israel.

The first prominent finding in this study was that reading Hebrew is faster and more accurate than reading Arabic beyond the native language (Arabs as Jews) and beyond the type of test (reading words and non-words). In this context, it is important to note, that even though acquisition of the Hebrew orthography is characterized by some level of complexity due to for example the similarity in the shape of the letters, the acquisition of the Arabic orthography is very much more complicated. Besides for the diglossia of the Arabic language, there is an additional complexity stemming from the similarity in the shape of letters, number of dots above or below, the connection between the letters, together with the changing shape of letters depending on their location within the word. Thus, our data bring additional evidence that this complexity influences both reading accuracy and reading rate among the two groups (Arabic and Hebrew speakers). This finding is important and is joined with earlier findings that dealt with the status of literary Arabic language for Arabic readers as well as the formative difficulty of Arabic orthography (Eviatar, Ibrahim, \& Ganayim, 2004; Ibrahim Eviatar \& Aharon Peretz, 2002; Maamouri, 1998; Saiegh-Haddad, 2003).

This central finding relates to fundamental differences between the two types of orthographies in Arabic (connected words versus nonconnected words) and Hebrew (words with similar versus words with dissimilar letters). In this comparison, it was found that among Arabic speakers, reading words and non words in Arabic with disconnected letters is more accurate and faster than reading words and non-words with connected letters among either group. This finding emphasizes the difficulty in reading words and non-words composed of connected letters and basically of similar and connected letters - a specific quality of Arabic orthography. This finding is in line with the findings of Ibrahim et al. (2002) who compared the spatial identification of Arabic letters with Hebrew letters. Even so, in the same area (but inside participants), differences were found among native Hebrew speakers; only in the speed based on the type of word (groups of words and non-words separate by the type of the orthographical information). However, there were no differences in the accuracy of reading words and non words (with similar and dissimilar letters). Among Hebrew speakers, it was found that the speed of reading words with similar letters is slower than reading words and non words with dissimilar letters. The matter of the similarity of the shape and feature of letters was also examined in Arabic language. Shimron \& Navon (1982), argued that in comparison to other languages, all letters in Hebrew are quadrangular and similar, such as English. According to these researchers, letters in Hebrew are mostly at one line this affects the ability to identify word. When letters are more similar, it is more difficult to identify them compared to dissimilar letters (Shimron \& Navon, 1982). Therefore in comparing Arabic and Hebrew, the speed of Hebrew speakers in reading words with similar letters in Hebrew is faster than the speed of Arabic speakers and native Hebrew speakers in reading words with similar and connected letters. It should be noted that the similarity in the shape of letters in Hebrew leads to a relative delay in indentifying words but not making error. Although the similarity in Arabic orthography (the shape of letters, the number of dots above and under, the connection between them, together with the change of their shapes based on their positions in the word) affects the accuracy and speed of reading among the two groups. This result is in consistency with earlier studies conducted by Eviatar and her colleagues (2004), who suggested that there are other factors which may add special difficulty when reading in Arabic leads to slower reading and making errors (Eviatar, Ibrahim, \& Ganayim, 2004). Beyond that, at initial presentation, the connected items (which were matched for diacritical complexity) were actually read more quickly than the non-connected items. This finding is consistent with Abdelhadi et al. (2011) who also found a speed advantage for words with connecting letters among skilled adult readers of Arabic performing a visual search task. The authors attributed this advantage to the fact that most printed words in Arabic consist of ligatured letters rather than non- ligatured letters. The present data, therefore, replicates this finding and extends it to young readers performing a standard word pronunciation task. In a related issue, Ibrahim and Eviatar (2012) tried to determine if the processing of Arabic orthography seems to make different demands on the cognitive system both in beginning and in skilled readers while recognizing Arabic letters compared to Hebrew letters. The researchers used behavioral measures of performance asymmetries in a divided visual field paradigm. There results show that Arabic orthography specifically disallows the involvement of the RH in letter identification, even while the RH of the same participants does contribute to this process in English and in Hebrew. The results were attributed to the additional visual complexity that characterizes Arabic orthography.

\section{Conclusion and Future Research}

The present study investigated $3^{\text {rd }}$ and $4^{\text {th }}$ grade bilingual Arabic/Hebrew-speaking learners in relation to visual factors which are central to issues of second language learning. While we did not aim to propose an explanatory model of learning to read in second language, the findings of the present study support previous findings suggested that measures of speed and accuracy of reading in Hebrew among Arabic speakers were 
significantly higher than measures of reading in Arabic among Hebrew speakers. Our conclusion was that Hebrew speakers did not succeed in transferring their proficiency and success in reading in their mother tongue to success in reading the second language. In view of the fact that bilingual schools use similar method in teaching the two languages, this allow us to conclude that Hebrew speakers did not succeed in transferring their good ability in reading their mother tongue to reading the second language, due to the unique nature of the Arabic orthography. Turning to reading disabled (or dyslexic) children, Breznitz (2003) argued that the inefficiency of reading process in this population derives not only from problems of accuracy and timing inside a specific processing system but also from interaction of information between systemic processes (i.e., the visual-orthographical system). The findings regarding learners' proficiencies in second language (Arabic or Hebrew) contribute to debates regarding the best methods or the strategies that might be chosen to teach learning to read second language. The findings of the present study rather suggest that, it is useful to continue to explore the cognitive and neurocognitive basis in decoding writing systems and how type of orthography might affects some hitherto neglected aspects of second language learning and L2 proficiency.

\section{REFERENCES}

Abdelhadi, S., Ibrahim, R., \& Eviatar. Z. (2011). Perceptual load in the reading of Arabic: Effects of orthographic visual complexity on detection. Writing Systems Research, 3, 117-127. doi:10.1093/wsr/wsr014

Abu-Rabia, S. (2000). Effects of exposure to literary Arabic on reading comprehension in a diglossic situation. Reading and Writing: An Interdisciplinary Journal, 13, 147-157. doi:10.1023/A:1008133701024

Abu-Rabia, S., \& Siegel, L. S. (1995). Different orthographies, different context effects: The effects of Arabic sentence context inskilled and poor readers. Reading Psychology: An International Quarterly, 16, 1-19. doi:10.1080/0270271950160101

Amara, M., \& Mar'i, A. (2002). Language education policy: The Arab minority in Israel. Dordrecht/Boston/London: Kluwer Academic Publishers.

Bialystok, E. (2001). Bilingualism in development: Language, literacy, and cognition. New York: Cambridge University Press. doi:10.1017/CBO9780511605963

Azzam, R. (1993). The nature of Arabic reading and spelling errors of young children. Reading and Writing, 5, 355-385. doi:10.1007/BF01043112

Breznitz, Z. (2003). Speed of phonological and orthographic processing as factors in dyslexia: Electrophysiological evidence. Genetic, Social and General Psychology Monographs, 129, 183-206.

Cummins, J. (1979). Linguistic Interdependence and the Educational Development of Bilingual Children. Review of Educational Research, 49, 222-251.

Cummins, J. (1981). The role of primary language development in promoting educational success for language minority students. In California State Department of Education (Ed.), Schooling and language minority students: A theoretical framework (pp. 3-49). Los Angeles: Evaluation, Dissemination and Assessment Center, California State University.

Cummins, J. (2000). Language, power and pedagogy: Bilingual children in the crossfire. Clevedon: Multilingual Matters.

Eviatar, Z., \& Ibrahim, R. (2001). Bilingual is as bilingual does: Metalinguistic abilities of Arabic speaking children. Applied Psycholin- guistics, 21, 451-471. doi:10.1017/S0142716400004021

De Groot, A. M. B. (1992). Determinants of word translation. Journal of Experimental Psychology: Learning, Memory, and Cognition, 18, 1001-1018. doi:10.1037/0278-7393.18.5.1001

Ibrahim, R., \& Aharon-Peretz, J. (2005). Is literary Arabic a second language for native Arab speakers: Evidence from a semantic priming study. The Journal of Psycholinguistic Research, 34, 51-70. doi:10.1007/s10936-005-3631-8

Ibrahim, R., \& Eviatar, Z. (2012). Multilingualism among Israeli Arabs, and the neuropsychology of reading in different languages. Literacy Studies, 5, 57-74.

Ibrahim, R., Eviatar, Z., \& Aharon Peretz, J. (2002). The characteristics of the Arabic orthography slow it's cognitive processing. Neuropsycholgy, 16, 322-326. doi:10.1037/0894-4105.16.3.322

Ibrahim, R., Eviatar. Z., \& Aharon Peretz, J. (2007). Metalinguistic awareness and reading performance: A cross language comparison. The Journal of Psycholinguistic Research, 36, 297-317. doi:10.1007/s10936-006-9046-3

Ibrahim, R. (2009). The cognitive basis of diglossia in Arabic: Evidence from a repetition priming study within and between languages. Psychology Research and Behavior Management, 12, 95-105.

Maamouri, M. (1998). Language education and human development: Arabic diglossia and its impact on the quality of education in the Arab region. The Mediterranean Development Forum. Washington, DC: The World Bank.

Paradis, M. (2009). Declarative and procedural determinants of second languages (studies in bilingualism 40). Amsterdam: John Benjamins.

Rao, C., Vaid, J., Srinivasan, N., \& Chen, H. C. (2011). Orthographic characteristics speed Hindi word naming but slow Urdu naming: Evidence from Hindi/Urdu biliterates. Reading and Writing, 24, 679695. doi:10.1007/s11145-010-9256-9

Roman, G., \& Pavard, B. (1987). A comparative study: How we read Arabic and French. In J. K. O'Regan, \& A. Levy-Schoen (Eds.), Eye movements from physiology to cognition (pp. 431-440). Amsterdam: North Holland Elsevier.

Saiegh-Haddad, E. (2003). Linguistic distance and initial reading acquisition: The case of Arabic diglossia. Applied Psycholinguistics, 24, 115-135. doi:10.1017/S0142716403000225

Saiegh-Haddad, E. (2004). The impact of phonemic and lexical distance on the phonological analysis of words and pseudowords in a diglossic context. Applied Psycholinguistics, 25, 495-512. doi:10.1017/S0142716404001249

Saiegh-Haddad, E. (2005). Correlates of reading fluency in Arabic: Diglossic and orthographic factors. Reading and Writing: An Interdisciplinary Journal: An Interdisciplinary Journal, 18, 559-582. doi:10.1007/s11145-005-3180-4

Share, D. L., Jorm, A. F., Maclean, F., \& Matthews, R. (1984). Sources of individual differences in reading acquisition. Journal of Educational Psychology, 76, 1309-1324 doi:10.1037/0022-0663.76.6.1309

Shatil, E., Share, D. L., \& Levin, I. (2000). On the contribution of kindergarten writing to Grade 1 literacy: A longitudinal study in Hebrew. Applied Psycholinguistics, 28, 1-25.

Shimron, J., \& Navon, D. (1982). The dependence on graphemes and on their translation to phonemes in reading: A developmental perspective. Reading Research Quarterly, 17, 210-228. doi: $10.2307 / 747484$

Taha, H., Ibrahim, R., \& Khateb, A. (2012). How does Arabic orthographic connectivity modulate brain activity during visual word recognition: An ERP study. Brain Topography, 26, 292-302. doi:10.1007/s10548-012-0241-2

Taouk, M., \& Coltheart, M. (2004). Learning to read in Arabic. Reading and Writing, 17, 27-57. doi:10.1023/B:READ.0000013831.91795.ec 